\title{
8
}
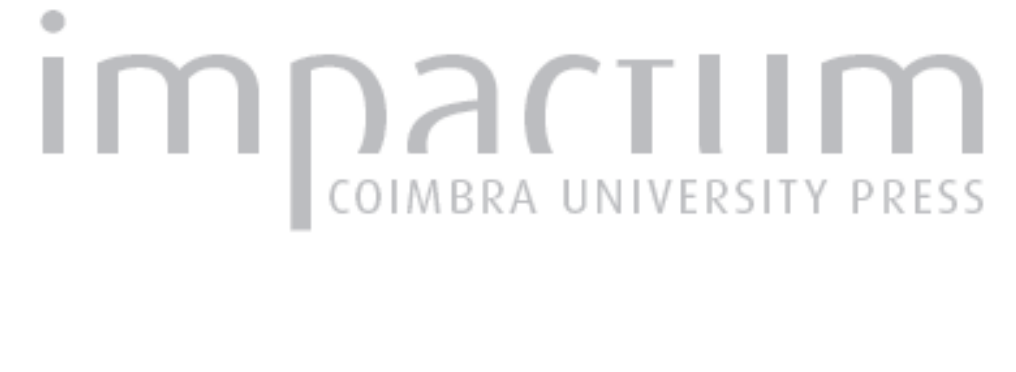

\section{Dar tempo ao tempo: o estudo do comportamento nas ciências do artificial e o problema das escalas temporais}

\author{
Autor(es): $\quad$ Silva, Porfírio \\ Publicado por: CIAS - Centro de Investigação em Antropologia e Saúde \\ URL \\ persistente: \\ URl:http://hdl.handle.net/10316.2/28692 \\ DOI: \\ DOI:http://dx.doi.org/10.14195/2182-7982_27_11 \\ Accessed : $\quad$ 26-Apr-2023 14:31:55
}

A navegação consulta e descarregamento dos títulos inseridos nas Bibliotecas Digitais UC Digitalis, UC Pombalina e UC Impactum, pressupõem a aceitação plena e sem reservas dos Termos e Condições de Uso destas Bibliotecas Digitais, disponíveis em https://digitalis.uc.pt/pt-pt/termos.

Conforme exposto nos referidos Termos e Condições de Uso, o descarregamento de títulos de acesso restrito requer uma licença válida de autorização devendo o utilizador aceder ao(s) documento(s) a partir de um endereço de IP da instituição detentora da supramencionada licença.

Ao utilizador é apenas permitido o descarregamento para uso pessoal, pelo que o emprego do(s) título(s) descarregado(s) para outro fim, designadamente comercial, carece de autorização do respetivo autor ou editor da obra.

Na medida em que todas as obras da UC Digitalis se encontram protegidas pelo Código do Direito de Autor e Direitos Conexos e demais legislação aplicável, toda a cópia, parcial ou total, deste documento, nos casos em que é legalmente admitida, deverá conter ou fazer-se acompanhar por este aviso.

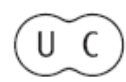




\section{Antropologia Portuguesa}

Volume $26-27 \cdot 2009-2010$

Departamento de Antropologia | Universidade de Coimbra

DARWINISMO:

revisitações, propostas, problemas 


\title{
Dar tempo ao tempo. O estudo do comportamento nas ciências do artificial e o problema das escalas temporais
}

\author{
Porfírio Silva ${ }^{1}$ \\ Instituto de Sistemas e Robótica, \\ Instituto Superior Técnico, Lisboa, Portugal \\ porfiriosilva@isr.ist.utl.pt
}

Resumo Neste texto sugere-se que as Ciências do Artificial podem contribuir com a sua dimensão experimental para o avanço da compreensão da dinâmica das interacções entre processos da história da vida que têm lugar em diferentes escalas temporais, como sejam a evolução de uma espécie, o desenvolvimento de indivíduos dessa espécie e a evolução cultural de uma sociedade. Para substanciar essa sugestão apresentam-se exemplos de trabalhos desenvolvidos no âmbito das Ciências do Artificial, uma constelação de abordagens científicas que procuram realizar em máquinas construídas por humanos certos comportamentos definidas como objectos de atenção por parecerem típicas dos próprios humanos ou de outros animais. Os exemplos apresentados são: primeiro, a Robótica Evolutiva, que procura obter robots que resultem de processos de evolução artificial; segundo, a Robótica do Desenvolvimento, que tenta implementar em plataformas robóticas alguns aspectos do complexo de processos que levam, em espécies que se reproduzem sexualmente, do zigoto ao indivíduo adulto; terceiro, experiências com a emergência de linguagens simbólicas em robots. A consideração destes exemplos conduz à identificação de um problema metodológico nas ciências do artificial: o problema das escalas temporais. Sugerimos que, para avançar na compreensão desse problema, as ciências do artificial beneficiariam de procurar inspiração na etologia.

Palavras-chave Ciências do Artificial; Nova Robótica; Robótica Evolutiva; Robótica do Desenvolvimento; linguagem para robots; escalas temporais.

Abstract This paper suggests that the experimental dimension of the Sciences
of the Artificial can contribute to the understanding of the dynamical interactions
between processes taking place at different time scales in the history of life, such
as the evolution of a species, the development of individuals, and the cultural
evolution of a society. This suggestion is substantiated with examples taken from
several lines of research within the framework of the Sciences of the Artificial, a

${ }^{1}$ A investigação do autor beneficia do apoio da Fundação para a Ciência e a Tecnologia (SFRH/BPD/35862/2007). 
constellation of scientific approaches seeking to make machines built by humans capable of a number of behaviours previously believed to be exclusive to human beings or other animals. The first example taken is Evolutionary Robotics, which uses techniques of artificial evolution to design autonomous robots. The second example is Developmental Robotics, which attempts to implement in robotic platforms some aspects of the complex processes that lead, in species that reproduce sexually, from a zygote to an adult individual. The third example is a series of experiments with the emergence of symbolic language in robots. A reflection on these examples leads to the identification of a methodological problem in the sciences of the artificial: the problem of time scales. We suggest that, to advance the understanding of this problem, the sciences of the artificial would benefit of seeking inspiration in ethology.

Key words Sciences of the Artificial; New Robotics; Evolutionary Robotics; Developmental Robotics; language for robots; timescales.

As comemorações, em 2009, do bicentenário de Charles Darwin e dos 150 anos d'A Origem das Espécies, foram oportunidade para testemunhar quão influente se tornou, quer em termos científicos quer a nível popular, a ideia de que a espécie humana (como as outras) é parte integrante da natureza, resultado de uma história que pode ser compreendida descartando o argumento do relógio e do relojoeiro transcendente - porque a existência de sistemas complexos não é necessariamente resultado do projecto deliberado de deuses ou de humanos, podendo bem ser largamente devida a mecanismos algorítmicos e desprovidos de finalidade. Há até tentativas recentes, oriundas nas ciências da sociedade e com bases epistemológicas diferentes da sociobiologia, para aplicar uma versão generalizada dos princípios darwinistas à evolução institucional, sob a designação de Darwinismo Generalizado (Hodgson e Knudsen, 2006; Aldrich et al., 2008).

O interesse científico e filosófico dessa ideia mede-se também pelas inúmeras janelas de investigação que abriu nas tentativas de compreender a vida em diferentes dimensões de variação, como história genética, epigenética, comportamental e simbólica. Essa orientação continua a ter um impacte assinalável na tentativa de compreendermos o comportamento, designadamente em etologia humana (Eibl-Eibesfeldt, 1997). Associamonos aqui à celebração desse desafio, mas propondo um percurso de certo modo tortuoso. Iremos pela via das Ciências do Artificial. 
Consideramos como "ciências do artificial" todas aquelas teorias e práticas científicas que procurem realizar em máquinas concebidas e/ou construídas pelos humanos certos comportamentos ou capacidades que tenham sido definidas como objecto de atenção por parecerem típicas dos próprios humanos ou de outros animais que encontramos na natureza. As Ciências do Artificial, que não são uma disciplina científica, mas uma constelação de disciplinas científicas, e uma constelação em evolução (Schopman, 1987; Gardner, 1985), podem ser exemplificadas, no século XX, pela Inteligência Artificial (IA) e pela Nova Robótica. Muitos praticantes das Ciências do Artificial entendem as suas experiências como (directa ou indirectamente) relevantes para compreender os próprios humanos. É assim que algumas tendências (como a IA clássica) focam aquilo que consideram específico dos humanos, por exemplo competências deliberativas de tipo simbólico altamente sofisticadas, enquanto outras (como a Nova Robótica) atendem preferencialmente à pertença dos humanos ao mundo animal e, desenvolvendo paralelos com outros animais, pretendem chegar a compreender essa dimensão infraestruturante da nossa humanidade.

Ora, no âmbito da Nova Robótica, um domínio das Ciências do Artificial particularmente produtivo nos últimos anos, têm decorrido esforços vários para compreender algumas dimensões da história da vida com base na sua implementação em máquinas. Vamos aqui, no que segue, exemplificar esse esforço com breves chamadas de atenção para três linhas de investigação. Primeiro, a Robótica Evolutiva, que procura obter robots que resultem de processos de evolução artificial. Segundo, a Robótica do Desenvolvimento, que tenta implementar em plataformas robóticas alguns aspectos do complexo de processos que levam, em espécies que se reproduzem sexualmente, do zigoto ao indivíduo adulto. Terceiro, experiências com a emergência de linguagens simbólicas em robots.

Um aspecto a merecer reflexão nas linhas de experiências robóticas que aqui exemplificaremos diz respeito às diferentes escalas temporais da história da vida que são próprias a cada uma delas. O que acabaremos por sugerir é que as Ciências do Artificial, designadamente a Nova Robótica, poderão de futuro participar num esforço de melhor compreensão da dinâmica das relações entre diferentes escalas temporais na história da vida natural. 


\section{A Robótica Evolutiva}

A ideia básica da Robótica Evolutiva (RE) concebe um robot autónomo como uma criatura artificial resultante de um processo de evolução artificial, que, ao longo de numerosas gerações, é guiado por uma função de aptidão que selecciona num determinado ambiente.

A criatura artificial é um robot constituído, por um lado, por um "corpo", o hardware, na maior parte das vezes uma máquina que se desloca sobre rodas, com certos sensores (por exemplo, infravermelhos para detectar obstáculos) e certos actuadores (por exemplo, os motores que fazem com que as rodas se movam); e, por outro lado, pelo sistema de controlo, o "sistema nervoso", o programa que determina o comportamento do robot. Trata-se aqui de robots autónomos, isto é, que são "lançados no mundo" com um certo "corpo" e um certo "sistema nervoso" e são deixados actuar segundo as possibilidades que assim lhes são dadas, sem controlo humano.

Evoluir sistemas de controlo. A maior parte das experiências de RE incidem sobre os sistemas de controlo dos robots. Os "sistema nervosos" destes robots são geralmente redes neuronais artificiais inspiradas nos cérebros biológicos. Na prática, uma rede neuronal artificial é um conjunto de "neurónios artificiais" organizados em camadas: a camada de entrada, com neurónios que recebem sinais dos sensores do robot em contacto com o ambiente; a camada de saída, com neurónios que transmitem comandos aos motores que accionam as rodas. Assim se implementa a coordenação sensório-motora de uma "criatura artificial". Nas redes neuronais pode haver camadas "escondidas" (sem contacto com o exterior), responsáveis por computação adicional. Cada neurónio está ligado a alguns outros por "conexões sinápticas", que podem ter mais ou menos peso, terem uma certa direcção, excitarem ou inibirem os sinais que transmitem. A forma como uma rede neuronal se comporta depende essencialmente da arquitectura das ligações e das características das conexões entre as unidades (Callan, 1999).

A metáfora biológica que inspira a RE é geralmente operacionalizada pela técnica do Algoritmo Genético (AG) ${ }^{2}$. Com esta técnica, dada uma população, cada indivíduo é representado por um cromossoma (uma cadeia finita de caracteres) composto por genes; os valores que podem assumir os genes são designados por alelos; o locus de cada gene é a posição que ele

${ }^{2}$ John Holland (1975) é o criador do AG. A descrição que a seguir se fará segue Mitchell, 1998. 
ocupa no cromossoma. A cada indivíduo corresponde um valor de aptidão, determinado pela função de aptidão e cujo significado varia em função do contexto. No tempo, teremos gerações sucessivas da população. Essas sucessivas gerações resultam da avaliação da aptidão de cada um dos indivíduos de uma geração e da construção da geração seguinte por métodos de selecção (copiar indivíduos de uma geração para outra dando aos mais aptos maior probabilidade de serem copiados) e por métodos de modificação (crossover, imitando o cruzamento por reprodução sexuada; mutação, consistindo na modificação aleatória de algum gene de alguns cromossomas). O resultado de cada iteração (selecção, crossover e mutação) é uma nova geração, que será, por sua vez, a população de partida da próxima iteração. Por acção da selecção e da recombinação, vai aumentando a aptidão média e diminuindo a diversidade da população (com a mutação a criar, ocasionalmente, novidade).

Em experiências de RE, cada cromossoma representa uma certa estrutura possível da rede neuronal artificial que será o sistema de controlo do robot (por exemplo, certas ligações entre sensores e motores). Pelo processo de evolução artificial são gerados sucessivamente diferentes "sistemas nervosos", que são instalados no robot e testados quando este é posto a desempenhar certas tarefas num certo ambiente. A avaliação desse desempenho dita a produção da geração seguinte, pelos processos mencionados. Normalmente só ao fim de um grande número de gerações se obtêm sistemas de controlo do robot que produzem comportamentos satisfatórios.

$\boldsymbol{O}$ robot Khepera. Algumas das experiências pioneiras em RE foram realizadas com o Khepera, um pequeno robot com duas rodas (cada uma accionada por um motor), levando a bordo baterias que garantem uma autonomia de 30 a 40 minutos (Figura 1). Toda a capacidade de computação disponível está num processador a bordo (Nolfi e Floreano, 2000).

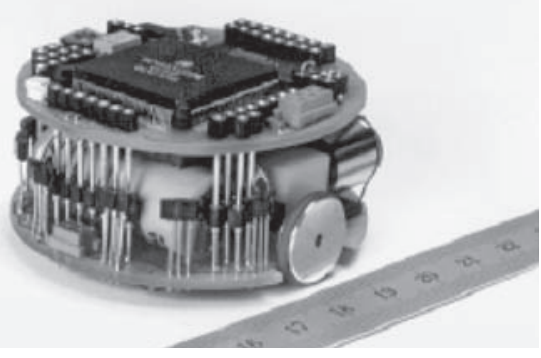

Figura 1. O robot Khepera (Floreano e Mondada, 1998: 1462). 
O Khepera tem uma arquitectura modular aberta: nele podem ser facilmente montados outros módulos com funções especializadas (por exemplo, um módulo de "visão"). O Khepera tem oito sensores de infravermelhos, que funcionam em modo passivo (medindo a quantidade de luz no ambiente) ou em modo activo (emitindo luz e medindo a luz reflectida, funcionando como sensores de proximidade). Alternando entre modo passivo e activo, servem como um duplo conjunto de sensores.

Numa das primeiras experiências do Khepera, implementando uma competência básica de navegação, o robot tinha de percorrer um pequeno labirinto sem colidir com as paredes. A evolução artificial foi constrangida por uma função de aptidão que premiava três componentes do comportamento da criatura artificial: a rapidez do movimento (soma da velocidade das rodas), o movimento em linha recta (rotação das duas rodas no mesmo sentido) e o evitamento de obstáculos (menor actividade dos sensores de proximidade). Resultou um robot que exibia o comportamento esperado pelos experimentadores.

Um Khepera que luta pela vida. Outra experiência desta série representa o valor da sobrevivência. Aqui (Floreano e Mondada, 1996), um Khepera deve passear-se por uma arena, tendo de se "reabastecer" de energia periodicamente para poder prosseguir (Figura 2).

Figura 2. O Khepera junto à estação de reabastecimento (Floreano e Mondada, 1996: 400).

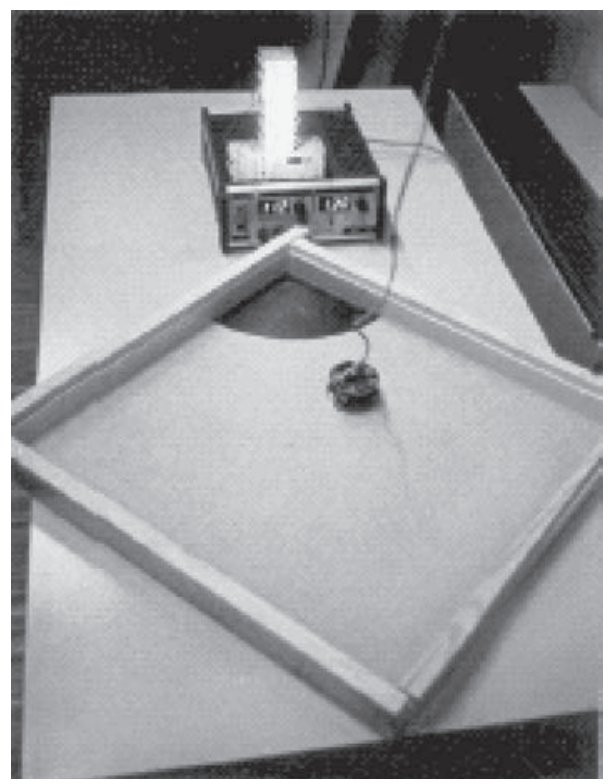


O robot está equipado com uma bateria simulada, com um controlador de nível de energia. A "estação de reabastecimento de energia" é uma área do chão pintada num dos cantos da arena. Próximo, encontra-se uma torre com lâmpadas viradas para a arena, que constitui a única fonte de luz. $\mathrm{O}$ robot está equipado com oito sensores infravermelhos de proximidade, dois sensores infravermelhos de luz ambiente, um sensor montado na placa inferior do robot e virado para baixo que indica sem ambiguidades quando o robot está ou não na estação de energia. O sistema de controlo do robot é uma rede neuronal artificial, com um estrato de entrada com 12 neurónios correspondentes às doze funções sensoriais mencionadas (incluindo o controlador de bateria), um estrato de saída com dois neurónios (um para cada um dos motores) e um estrato interno com cinco neurónios com conexões recorrentes. A função de aptidão premiava explicitamente a rapidez com que o robot se movia e a capacidade de evitar as colisões; o valor de aptidão era calculado de forma cumulativa, o que premiava $o$ tempo de sobrevivência (mas era penalizado o comportamento de permanecer quieto na zona de abastecimento). A função de aptidão não continha, portanto, qualquer referência à necessidade de reabastecimento ou à zona onde isso era possível. A experiência evolutiva durou 240 gerações (durante dez dias) e conseguiu-se chegar a uma situação de elevado desempenho na tarefa atribuída: os robots descobriram que tinham de passar pela estação de reabastecimento de energia periodicamente, passaram a ir lá só quando realmente era necessário, passaram a estar lá cada vez menos tempo, prolongaram o seu tempo de vida.

Predador e Presa: co-evolução competitiva. Outra experiência representa uma situação de co-evolução competitiva ${ }^{3}$. Aqui, duas ou mais espécies, mutuamente relevantes, evoluem interagindo num ambiente partilhado, tornando a paisagem de aptidão altamente dinâmica. Temos um "Predador" e uma "Presa", Kheperas modificados para representarem a pertença a espécies diferentes, dotados de capacidades sensoriais e motoras diferenciadas (Figura 3).

${ }^{3}$ Floreano, Nolfi e Mondada (1998). A mesma experiência mas em simulação num computador tinha sido descrita em Floreano e Nolfi (1997). 
Figura 3. Imagem the Kheperas modificados (Floreano e Nolfi, 1997: 379).

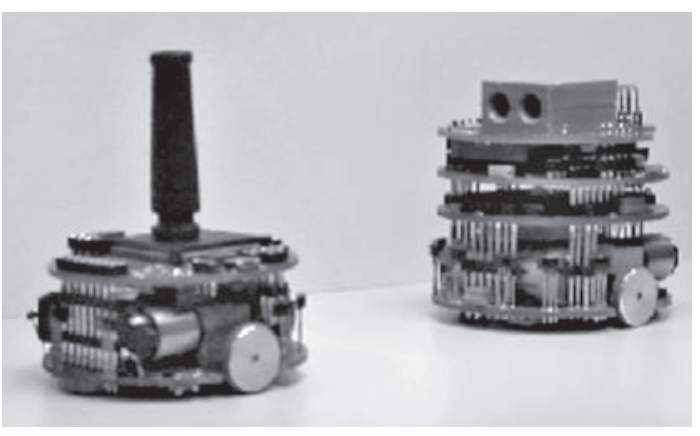

O módulo básico dos dois Khepera tem a habitual bateria de sensores. O Predador (à direita na imagem) está equipado com um módulo de visão. A Presa (à esquerda) tem uma protuberância escura que pode ser detectada pelo Predador em qualquer localização no ambiente comum (dentro do ângulo de visão), mas a sua velocidade máxima é o dobro da do Predador. $\mathrm{O}$ ambiente é uma arena cercada por muros brancos altos, que facilitam a detecção da protuberância da presa pelo predador.

A função de aptidão apontava directamente para o resultado que se pretendia obter, sem incluir quaisquer considerações acerca do modo como o robot devia lá chegar. No caso do predador, os valores aumentavam com a rapidez em tocar a presa. No caso da presa, o valor de aptidão era tanto mais alto quanto mais tempo evitasse o toque do predador. Na figura 4 apresentase um exemplo de co-evolução das estratégias do predador e da presa.
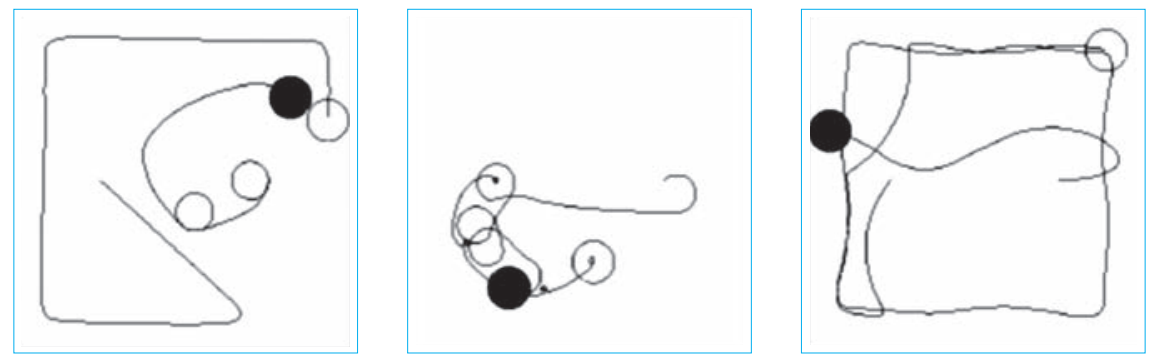

Figura 4. Exemplo de co-evolução das estratégias do predador e da presa (Floreano et al., 1998: 521).

O disco preto representa o predador, o disco branco a presa. À esquerda: ao fim de 13 gerações, a presa tem um comportamento muito simples (desloca-se ao longo do muro e muda de direcção quando encontra 
um canto) e o predador limita-se a detectar a presa e a segui-la, embora a desvantagem em termos de velocidade impeça por vezes a captura. Ao centro: ao fim de 20 gerações, a presa gira com velocidade em pequenos círculos para se proteger do predador. À direita: ao fim de 22 gerações, o predador desenvolveu uma estratégia mais sofisticada: mantém-se perto do muro e ataca quando detecta a presa ao seu alcance, o que faz com que, por vezes, seja incapaz de travar a tempo e esbarre contra o muro.

Os autores (Floreano et al., 1998; Nolfi e Floreano, 1998) consideram que estas experiências mostram que a evolução artificial tem potencialidades para permitir projectar controladores robóticos, capazes de enfrentar situações complexas e dificilmente previsíveis em muitos dos seus detalhes relevantes, de uma maneira que seria muito difícil ou impossível de conceber directamente por projectistas humanos.

Corpos Evolutivos. Embora desde os alvores da Robótica Evolutiva os seus pioneiros tivessem presente a conveniência de fazer co-evoluir "cérebros" (sistemas de controlo) e morfologia (plataforma robótica), a prática experimental era mais limitada: fazer evoluir controladores robóticos para uma determinada plataforma (real ou simulada) e descarregar posteriormente o controlador na plataforma, assim dotando o robot de um certo comportamento. Ficamos, deste modo, sem uma verdadeira representação da adaptação dos organismos de uma população onde as pressões do ambiente se exercem, não apenas sobre o sistema nervoso, mas sobre todo o corpo de uma criatura. É com base neste diagnóstico que alguns autores se concentram na evolução de estruturas físicas completas que poderiam ser corpos de robots. Um dos primeiros projectos a tratar da evolução de estruturas físicas dotadas de movimento, que possam ser encaradas como criaturas artificiais, é o GOLEM ("Genetically Organized Lifelike Electro Mechanics") (Lipson e Pollack, 2000).

Neste projecto parte-se de blocos de construção elementares, que neste caso são pequenas barras (para o "corpo") e neurónios artificiais (para o "sistema nervoso"). As barras conjugam-se para formar estruturas. Mudando o número de barras, o seu comprimento e as ligações entre elas, o comportamento da estrutura é modificado (umas barras serão rígidas, outras articuladas, algumas evoluirão para actuadores). Os neurónios podem conectar-se livremente, desenvolvendo sinapses, formando uma rede neuronal artificial. Os neurónios podem ligar-se a barras. O neurónio que controla uma barra pode determinar que ela tenha um comprimento variável, sendo implementado mais tarde com um motor que simula um "músculo" que contrai e distende uma "perna" mecânica (Figura 5). 


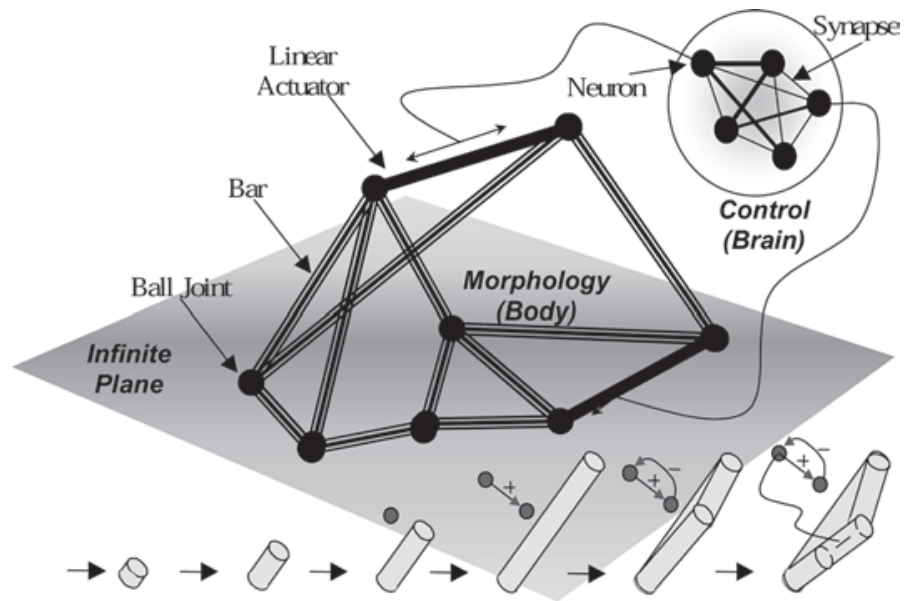

Figura 5. Esquema de uma criatura (Lipson e Pollack, 2000: 974).

O processo começa em simulação. Nesta fase, os corpos são representados apenas por pontos e linhas. A função de aptidão premeia a capacidade de locomoção de cada máquina: a distância que ela percorre num determinado tempo. Toda a simulação assenta num modelo da realidade física terrestre. Passa-se, depois, à fase de "solidificação", na qual, ainda em simulação, as criaturas são transpostas para corpos virtuais com volume: barras, juntas, lugares reservados para encastrar os motores que implementarão os actuadores lineares. Passa-se depois à "materialização": a criatura é fabricada automaticamente (excepto os motores), por um processo de impressão 3D a quente (em termoplástico), utilizando tecnologia disponível comercialmente (Figura 6). Tal como podemos ver numa impressora de jacto de tinta o texto de uma página a ser impresso linha a linha, assim o "corpo" é impresso a três dimensões camada a camada, surgindo pré-montado numa estrutura física.

Figura 6. Resultado da impressão 3D de uma criatura (Fotos de http://demo. cs.brandeis.edu/golem/).

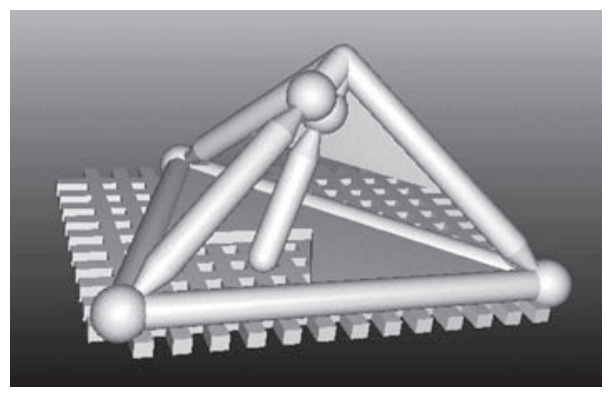


Esta fase de materialização termina encaixando manualmente os motores e ligando o sistema de controlo (que continua dentro do computador) à criatura (vejam-se os cabos na figura 7, necessários também ao fornecimento de energia). Não há quaisquer sensores nestas criaturas.
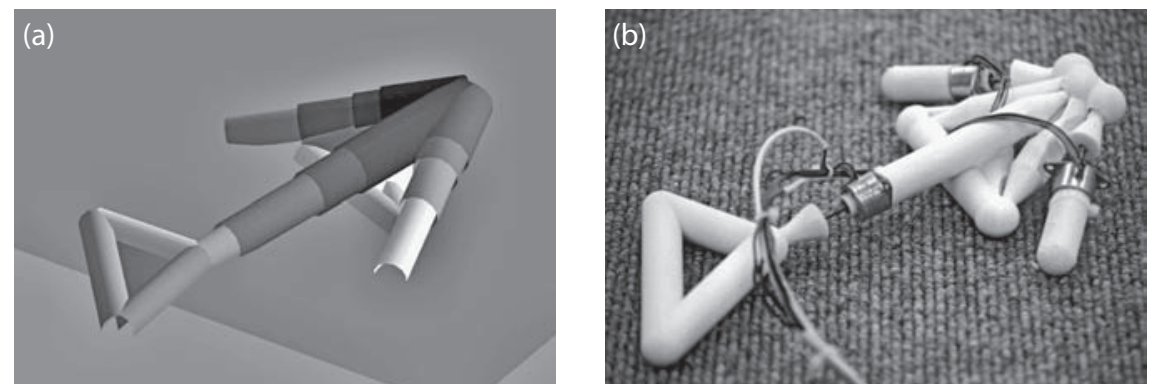

Figura 7. Enquanto os dois membros superiores empurram, o tronco central retrai-se (e vice-versa). (a). À esquerda, a "criatura" virtual. (b). À direita, depois de materializada. No robot finalizado, vêem-se os motores montados e os cabos que ligam ao computador externo onde está o sistema de controlo (Fotos de http://demo.cs.brandeis.edu/golem/).

Um dos aspectos interessantes deste trabalho, realçados por Brooks (2000: 947), é que o processo de fabrico permita, nas juntas dos “membros", que as esferas e os seus encaixes orbitais sejam construídos desde o início na sua forma final, isto é, as esferas já dentro do seu receptáculo, de tal forma que as partes nunca estiveram separadas e, se tivessem estado, não teriam podido juntar-se desta maneira sem se danificarem - o que, para Brooks (2000), faz lembrar a forma como os sistemas biológicos crescem (Figura 8).

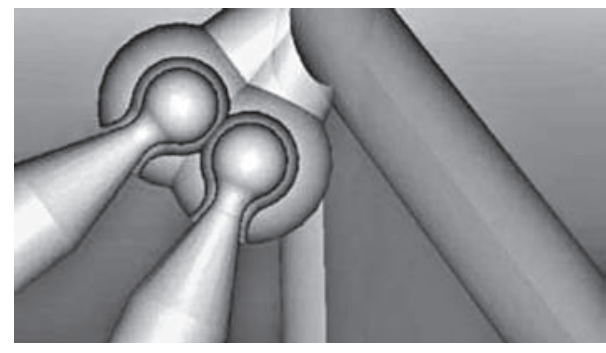

Figura 8. Pormenor de uma junta (Fotos de http://demo.cs.brandeis.edu/ golem/).

No mesmo texto, Brooks (2000) critica que todo o processo evolutivo se passe dentro do computador (em simulação), sem qualquer avaliação do valor de adaptação no mundo físico; que o sistema de controlo nunca saia do computador (é ligado à criatura por um cabo); que, nestas condições, 
não haja qualquer retorno do mundo físico sobre o processo evolucionário. São exemplos relevantes das limitações destas experiências, se quisermos entrar em linha de conta com o realismo biológico.

\section{Desenvolvimento para robots}

A Robótica Evolutiva (RE), incidindo sobre "sistemas nervosos" ou "corpos" muito simplificados, procura incorporar em criaturas artificiais os processos naturais de apuramento adaptativo das espécies - mas acaba por chegar apenas, por assim dizer, a robots que já "nascem adultos". Todo o complexo de processos que, nas espécies que se reproduzem sexualmente, levam da célula única resultante da fecundação ao indivíduo adulto completamente formado, é ignorado. Essa falta de atenção ao desenvolvimento (pré-natal ou pós-natal) é o espaço que pretende ser ocupado pela Robótica do Desenvolvimento (RD), ou Robótica Epigenética, como resposta ao diagnóstico de que esse pode ser um entrave crucial às ambições das Ciências do Artificial. Como escrevem (Lungarella et al. 2003: 179): "A mera observação de que quase todos os sistemas biológicos - em diferentes medidas - passam por processos de amadurecimento e desenvolvimento, comporta a convincente mensagem de que o desenvolvimento é a principal razão pela qual a adaptabilidade e a flexibilidade dos sistemas compostos orgânicos transcende a dos sistemas artificiais". O argumento não será suficiente para conferir ao processo de desenvolvimento um lugar determinado na formação de seres biológicos complexos, uma vez que outros processos (como o metabolismo ou a procriação) são também característicos desses seres. Não obstante, até pela conjugação de maturação física e cognitiva nesse processo de desenvolvimento, parece ser correcto identificá-lo como uma diferença importante entre criaturas artificiais e criaturas das espécies naturais.

A RD não constitui ainda um campo de investigação bem delimitado e permanece muito heterogéneo. Autores diferentes concentram-se em momentos e aspectos distintos da interacção entre organismos e ambiente no desenvolvimento de um organismo. Por exemplo, na esteira de Teuscher e colaboradores (2003) vem uma preferência por abordagens centradas na concorrência de três processos (filogenia, ontogenia, epigenia) que, em escalas temporais diferentes, conformam os organismos adultos de uma dada espécie. Já Zlatev e Balkenius (2001) induzem uma abordagem mais interessada pelos aspectos psicológicos do desenvolvimento pós-natal. De 
qualquer modo, a RD difere de outras visões das Ciências do Artificial em aspectos essenciais, dos quais passamos a destacar alguns que consideramos mais significativos.

Primeiro, a RD sublinha sem concessões o papel do corpo na cognição: seja qual for a base inata, os mecanismos cognitivos virão a ser o resultado dos processos de interacção entre um corpo com certas características sensório-motoras e um mundo em movimento em que esse corpo tem de se desembaraçar.

Segundo, o desenvolvimento é um processo incremental, em que o que é possível num estádio depende do que se adquiriu em estádios anteriores - mas, igualmente, um processo não linear, com instabilidades, regressões, mudanças de ritmo, ritmos desencontrados em dimensões diferentes.

Terceiro, o desenvolvimento cognitivo é condicionado, mas também apoiado, por constrangimentos do corpo: as limitações sensoriais, se limitam as capacidades cognitivas, também protegem o seu carácter incremental (por exemplo, as limitações visuais do recém-nascido permitem que só tenha que lidar com um fluxo restrito de dados visuais, de acordo com o desenvolvimento incipiente do sistema neuronal).

Quarto, o desenvolvimento não depende de um controlador central que organize todo o processo, sendo em muitos aspectos mais um conjunto de processos de auto-organização, ligados a diferentes aspectos da interacção com o ambiente. O que é interessante é que processos centralizados, favorecidos por certas correntes mais clássicas das Ciências do Artificial, provavelmente seriam incapazes de lidar com os mesmos problemas. Atente-se, por exemplo, no que significa o "mero" controlo da estrutura constituída pelo esqueleto e pelos músculos. Mesmo que cada um dos cerca de 600 músculos do corpo humano só tivesse duas posições (contraído ou relaxado), isso faria com que o número de possíveis configurações do sistema $\left(2^{600}\right)$ fosse superior ao número de átomos no universo conhecido. Esse tipo de complexidade dos organismos vivos sugere que o projecto explícito de criaturas artificiais com sistemas de controlo centralizados pode ser impraticável.

Quinto, o desenvolvimento (pós-natal) depende essencialmente de processos sociais, já que ele acontece graças a um número massivo de interacções continuadas com outros indivíduos, principalmente da mesma espécie, adultos ou em estádios ulteriores de desenvolvimento, que proporcionam naturalmente (na maior parte dos casos sem um treino específico) os desafios adequados ao carácter incremental do processo. Por essa via, 
provavelmente impossível de formalizar de maneira a poder ser automatizada, a espécie acolhe os seus espécimes - de forma social (apesar de a dimensão social ter demorado tanto a começar a ser sequer pensada pelas Ciências do Artificial).

Uma breve menção ao projecto RoboCub ${ }^{4}$ ilustrará alguns dos aspectos mais interessantes a esperar da RD. O "filhote-robot" é um projecto internacional (iniciado em 2004) que construiu uma série de robots designados como iCub. Trata-se de um robot humanóide representando as características físicas e cognitivas de uma criança humana de três anos e meio, capaz de gatinhar e de manipular objectos - e de, assim, aprender pela interacção com humanos. O seu "corpo", com um elevado número de graus de liberdade (53), nove dos quais nas mãos com três dedos independentes e outros dois para estabilidade e suporte, seis dos quais nas pernas que deverão permitir locomoção bípede; as câmaras digitais para a visão, os microfones e outros sensores; no futuro uma pele artificial; e um poder computacional fornecido por máquinas exteriores
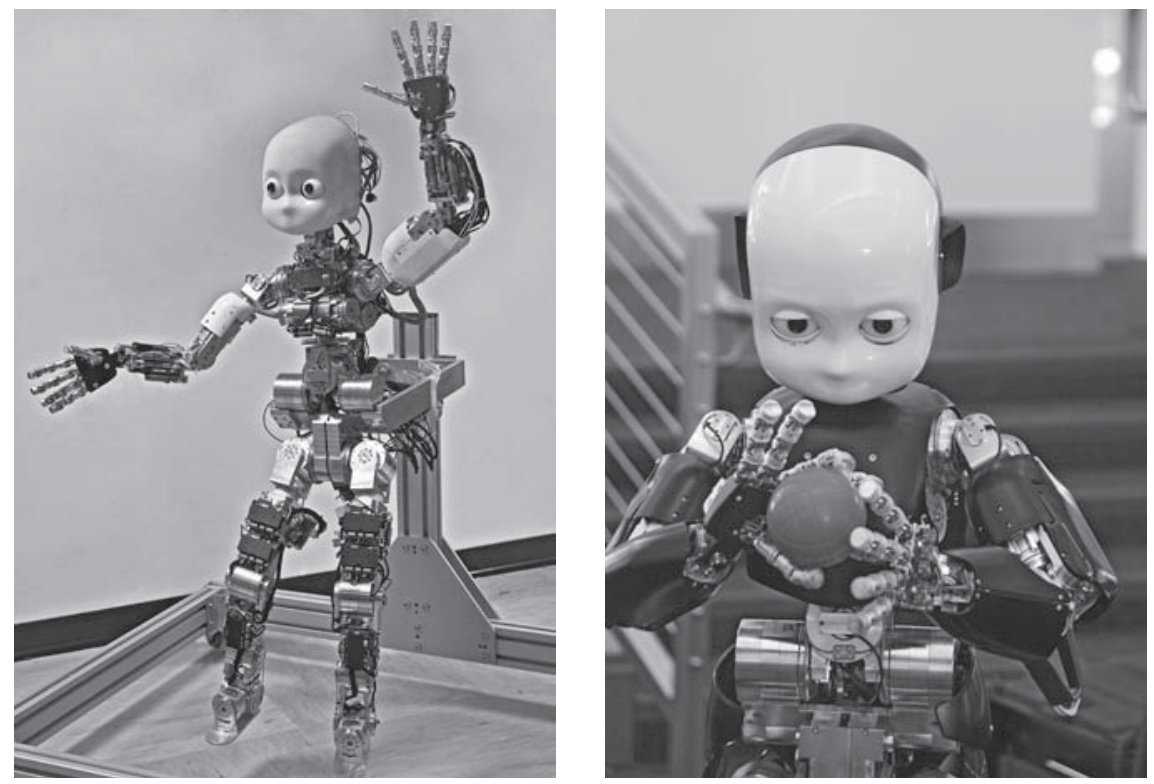

Figura 9. O robot iCub.

${ }^{4}$ Para uma primeira apresentação geral do projecto (Sandini et al., 2004). Toda a informação posterior, também sobre robot iCub, incluindo as imagens, foi recolhida no site oficial do projecto, em http://www.robotcub.org/. 
ligadas por cabos - estão já a permitir experiências de interacção com humanos dirigidas para perceber melhor como é que as capacidades sensório-motoras e cognitivas de um espécime jovem resultam dessa interacção com outros membros de uma espécie natural.

Pode pensar-se que só um antropocentrismo exacerbado justificaria querer experimentar com processos de desenvolvimento num "filhote humanóide". Contudo, cabe notar que, dada a condição (humana) dos experimentadores, a interacção informal do robot com membros de uma espécie natural é mais acessível nestas circunstâncias. Designadamente, só com humanos é possível conversar acerca da sua participação nesta interacção. É claro que o iCub não é um robot que possa já ter uma interacção natural com humanos no seu ambiente habitual, estando confinado a laboratórios e ao contacto com experimentadores. Contudo, é um avanço prometedor na experimentação de uma ideia estimulante: grande parte das aquisições pós-natais dos indivíduos de determinadas espécies é devida à interacção apropriada com outros indivíduos em estádios mais avançados de desenvolvimento.

\section{Linguagem para robots}

Aspecto essencial da Robótica do Desenvolvimento é a sua pertença à chamada Robótica Social: um conjunto heterogéneo de abordagens robóticas que não se limitam a conceber indivíduos artificiais, mas a conceber interacções entre eles (e, eventualmente, com humanos). Outro tipo de abordagem que também pode ser considerada Robótica Social é a que estuda agentes robóticos enquanto produtores e utilizadores de representações simbólicas sofisticadas.

Luc Steels, contrariando o domínio da IA pela "robótica baseada em comportamentos" nos anos 1990, propõe voltar a pensar seriamente no papel das representações simbólicas na inteligência geral, nomeadamente voltando a trabalhar o papel da linguagem simbólica na comunicação entre agentes (Steels, 2003). Assim, desenvolve a partir de 1995 uma investigação sobre as origens da linguagem, partida da ideia de que uma comunidade de utentes de uma linguagem pode ser vista como um sistema adaptativo complexo que resolve colectivamente o problema de desenvolver uma forma de comunicação partilhada. 
Com uma vaga inspiração wittgensteiniana, a equipa de Steels desenvolve "jogos de linguagem adaptativos", envolvendo um falante e um ouvinte, bem como um contexto composto de agentes, objectos e situações, onde podem ser usados meios extra-linguísticos, como apontar. Cada jogo de linguagem tem os seus objectivos. Exemplos: o falante deve levar o ouvinte a executar uma determinada acção; o falante deve obter certa informação do ouvinte. Vamos aqui dar atenção a uma primeira experiência com robots, especificamente num "jogo de designação" (Steels e Vogt, 1997).

A dinâmica central do "jogo de designação" consiste na criação de um léxico partilhado a partir de léxicos privados de cada robot, a par de "jogos de discriminação" assentes nas capacidades de categorização sensorial dos robots. Nesta experiência usam-se pequenos robots móveis autónomos, cada um transportando a sua própria bateria e equipado com dois motores laterais, com emissores de infravermelhos e com uma colecção de sensores que inclui sensores de infravermelhos, de luz visível, de toque, de carga da bateria. Os robots comunicam por um canal rádio. Os robots devem tratar de fazer recarregar as suas próprias baterias, para a própria "sobrevivência".

O "jogo de designação" desenrola-se em seis etapas, seguidamente descritas em termos gerais.

Entrar em contacto. Os robots, inicialmente colocados a vaguear pela arena da experiência, encontram-se e usam os seus emissores e receptores de infra-vermelhos para se colocarem frente a frente.

Identificar tópicos de conversa. Os dois robots começam por tratar de adquirir uma percepção partilhada do ambiente próximo. Cada robot dá uma volta de 360 graus sobre si mesmo, registando o fluxo de dados que esse movimento provoca em cada um dos seus sensores. Diz-se que um robot localiza um objecto quando o apanha num ponto de cruzamento de um par de sensores do mesmo tipo (colocados simetricamente dos lados do robot). O fluxo de dados de todos os sensores acerca de um desses pontos contribui para a caracterização desse objecto. Os tipos de sensores que contribuem para esse perfil definem um "conjunto de traços" que pode servir para categorizar o objecto. Por este processo, cada agente identifica um conjunto de objectos no ambiente próximo, que passam a constituir o contexto; cada objecto tem associado um pacote de valores de dados sensoriais em vários modos. Qualquer um desses objectos, mais os próprios robots, constitui um possível tópico de conversa. O robot falante escolhe dessa lista, aleatoriamente, um tópico de conversa e chama para ele a atenção do robot ouvinte (por meios 
extra-linguísticos, como "apontar": o robot falante vira-se para o objecto em causa). Se o robot falante não se mexer nesta fase, isso significa que ele próprio é o tópico escolhido. O robot ouvinte, para identificar o mesmo tópico, calcula, com base nas emissões de infra-vermelhos do robot falante durante o movimento de "apontar", em que quadrante se deve localizar o tópico proposto (considerando o diferente posicionamento relativo dos dois robots no ambiente, uma vez que a posição de partida é face a face). Quando estes movimentos não resultam, o jogo falha.

Categorizar. Cada robot procura como caracterizar o tópico de conversa em termos dos "conjuntos de traços" sensoriais disponíveis para esse objecto. Certos sensores apanharam esse objecto, outros não: só se podem usar os sensores que o apanharam. De entre os sensores que apanharam o tópico, alguns fornecem valores que não o distinguem de outros objectos (dois objectos que reflectem a mesma luz visível não são discriminados pelo sensor de luz visível). Certos sensores fornecem valores marcadamente diferentes para o tópico e para os restantes objectos, sendo esse os que melhor contribuem para a tarefa de categorização. Desta maneira, cada agente categoriza as suas experiências sensoriais dos diferentes objectos presentes no contexto, em termos das características que os seus sensores são capazes de discriminar. Esta etapa corresponde a um "jogo de discriminação".

Codificar. Com base no "jogo de discriminação", o robot falante escolhe aquele conjunto de traços que melhor sirva a identificação do tópico de conversa, por contraste com os outros objectos no contexto, e compõe uma expressão (um conjunto de palavras, de entre aquelas que pertencem ao léxico de que o robot já está dotado à partida) que represente esse tópico face a esse conjunto de características. Enviando, por um canal rádio que liga os robots, essa expressão, o robot falante produz a "fala" que designa o objecto escolhido como tópico de conversa. O léxico é uma memória associativa na qual existe um conjunto de pares palavra/significado. Um "significado" é um "conjunto de traços" sensoriais com certos valores. Cada agente tem um léxico próprio, que é privado (não pode ser consultado pelos outros). $\mathrm{O}$ agente conta as vezes que cada item do léxico é usado e o (in)sucesso de cada uso, preferindo usar os mais frequentemente usados e os que tenham uma taxa de sucesso superior. O léxico evolui com o envolvimento dos agentes em "jogos de discriminação": se um falante não tiver uma palavra para um certo conjunto de características, pode criar uma palavra e associála a esse significado. 
Descodificar. O robot ouvinte procura no seu léxico as palavras constantes da expressão (fala) emitida pelo agente falante e tenta identificar como é que elas remetem para características dos objectos, procurando assim verificar para que perfil de objecto remete aquela expressão. Este processo pode enfrentar várias dificuldades. Se um ouvinte não tiver no seu léxico uma palavra usada pelo falante, tentará inferir que característica é que o outro poderá estar a falar. Uma vez que conhece (por meios extra-linguísticos) o tópico de conversação, a tarefa é maximamente simples se o tópico for descrito com base num único traço sensorial (a palavra pronunciada refere-se a esse traço). Se conhecer algumas mas não todas as palavras usadas pelo falante, o exercício é mais arriscado e pode originar ambiguidades no léxico (que podem ser resolvidas em usos ulteriores). Se o ouvinte descodificar uma expressão que não corresponde ao conjunto de traços sensoriais que ele esperava que fosse usado para descrever o tópico de conversa, é porque há uma diferença entre a sua memória de pares palavra/significado e a do falante.

Retroagir. O agente ouvinte compara o perfil de objecto que resultou da descodificação da "fala" do outro robot com o perfil de objecto de que estava à espera. Se eles correspondem, o jogo de designação teve sucesso; caso contrário, fracassou.

Estas experiências acerca de linguagem em agentes artificiais encorpados assumem que, se quisermos chegar a alguma forma de fundação intrínseca do significado dos símbolos usados pelos robots, evitando que caiba aos humanos fornecer os símbolos e a respectiva interpretação, temos de permitir que os robots tenham experiências sensório-motoras e que seja nelas que os símbolos tenham a sua fundação.

Uma série de experiências posteriores (Talking Heads) ampliaram esta linha de investigação ${ }^{5}$. Uma "cabeça falante" é uma câmara vídeo montada num suporte com motores que lhe permitem mover-se. Numa experiência há duas cabeças, posicionadas lado a lado e viradas para a mesma cena. A cena contém vários objectos (alguns em movimento) com várias formas e tamanhos, sobre os quais as "cabeças" "conversam".

O processo de categorização perceptiva anteriormente mencionado inclui agora a visão. Vários módulos especializados em tratamento de imagem detectam certas características de uma cena, separam diferentes segmentos da mesma com base nos diferentes valores que exibem para essas caracterís-

${ }^{5}$ Belpaene et al. (1998) relata o início destas experiências. 
ticas e constroem ontologias (assumem a existência de certos objectos com certos perfis na cena em causa). Alguns pormenores de uma versão destas experiências (Steels, 2001) ajudam a compreender o processo (Figura 10).

(a)

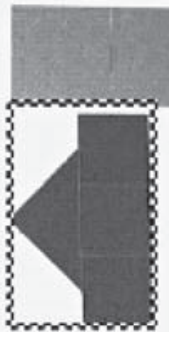

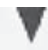
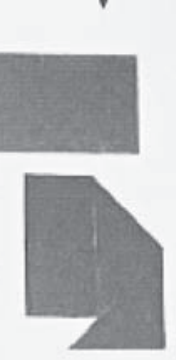

(b)

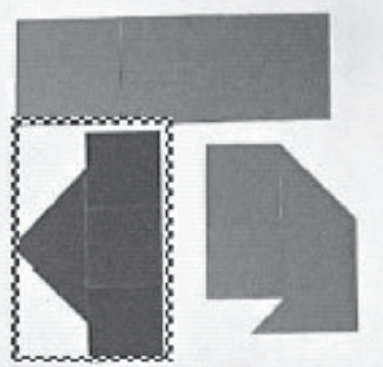

Figura 10. As imagens que dois agentes capturaram ${ }^{6}$, estando assinalado o tópico de conversa escolhido pelo"falante" (Steels, 2001: 20).

A tabela 1 exibe os dados que o "falante" obtém acerca dos três objectos na imagem (a). A tabela para o "ouvinte" (imagem b) terá valores próximos mas ligeiramente diferentes.

Tabela 1. Dados que o "falante" obtém acerca dos três objectos na imagem (a).

\begin{tabular}{|c|c|c|c|c|c|c|c|c|c|c|}
\hline Objecto & $\begin{array}{c}\text { Horizontal } \\
\text { do centro }\end{array}$ & $\begin{array}{c}\text { Vertical } \\
\text { do centro }\end{array}$ & Altura & Largura & Angulosidade & Vermelho & Verde & Amarelo & Azul & Brilho \\
\hline 1 & 0,37 & 0,71 & 0,48 & 0,21 & 0,45 & 0,17 & 0,00 & 0,00 & 0,39 & 0,28 \\
\hline 2 & 0,70 & 0,69 & 0,38 & 0,22 & 0,45 & 0,98 & 0,00 & 0,52 & 0,00 & 0,36 \\
\hline 3 & 0,51 & 0,31 & 0,21 & 0,51 & 0,70 & 0,00 & 0,99 & 0,73 & 0,00 & 0,46 \\
\hline
\end{tabular}

Com base nestes dados, cada agente forma perfis de características dos objectos. No exemplo das figuras geométricas acima, a característica "azul" distingue nitidamente o tópico de conversação dos outros objectos. $\mathrm{O}$ falante usa essa característica para identificar o objecto de que falará. Tendo três "palavras" no seu léxico para esta característica, escolhe "Xagadude". O "ouvinte", que sabe qual é o tópico de conversa e que também elege o "azul" como a característica que melhor serve uma categorização que o distinga nitidamente, não tem nenhuma palavra no seu léxico para esta característica. Adiciona "Xagadude" ao seu léxico, com este "significado".

${ }^{6}$ As imagens originais são coloridas: a de cima é esverdeada, a de baixo à esquerda é azulada, a de baixo à direita é avermelhada. 
Assim se vão construindo vocabulários partilhados, fundados nos dados sensoriais das máquinas.

Numa fase posterior, a experiência das Talking Heads ganhou outra dimensão. Havia instalações com pares de câmaras vídeo e cenas do mesmo género (figuras geométricas coloridas sobre um fundo branco) em várias partes do mundo, ligadas pela Internet, podendo qualquer pessoa criar agentes e introduzi-los na experiência. Um agente, chegando a uma instalação, "ocupava" uma das câmaras de vídeo e começava um jogo de linguagem com a "cabeça falante" local. Os experimentadores nas diferentes localizações faziam variar o conjunto de figuras colocadas na cena a seu cargo, tornando mais rica a experiência dos agentes em rede e mais rico o seu léxico. A conversa entre máquinas tornou-se uma "experiência de massas": perto de 6000 agentes foram lançados em 1999 e 2000 por pessoas exteriores à organização. Mesmo assim, acabou por emergir um léxico relativamente estável, devido ao facto de as palavras bem sucedidas em conversas passadas serem preferidas em conversas seguintes, enquanto as palavras que falhavam a comunicação tendiam a ser cada vez menos utilizadas. As palavras para características relativamente estáveis em todas as instalações das experiências (como vermelho, verde, azul, esquerda, direita, abaixo, acima) tornaram-se as mais usadas, enquanto as palavras para características muito dependentes das variações locais da experiência (como as que dependiam das condições de luz) tinham mais dificuldade em alcançar um uso geral (Steels et al., 2002).

Nesta experiência, o jogo de linguagem utilizado era um "jogo de adivinhar": o falante escolhe o tópico de conversa, mas, desta vez, não o "aponta" ao ouvinte. O falante produz uma fala, o ouvinte tenta adivinhar qual é o tópico e comunica a sua "aposta" ao falante, "apontando" para o objecto (o agente "aponta" fazendo "zoom" com a câmara vídeo sobre o objecto, movimento comunicado ao outro). Se o ouvinte apontou para o tópico que o falante tinha designado, o jogo teve sucesso; se o ouvinte apontou um objecto diferente, o falante "aponta" para o tópico, para elucidar o ouvinte. O ouvinte acrescenta a associação palavra/significado à sua memória associativa. O que se trata num "jogo de adivinhar" é o processo de descoberta do significado de uma palavra desconhecida.

As experiências desenvolvidas nesta linha são muito mais complexas do que aqui podemos dar conta, incluindo, por exemplo, a evolução da 
gramática $^{7}$. De qualquer modo, elas exemplificam claramente como as Ciências do Artificial podem abordar a dimensão simbólica da história da vida no nosso mundo.

\section{0 artificial e o problema das escalas temporais}

Esta exemplificação rápida de várias linhas de investigação em Nova Robótica a partir de algumas das suas experiências fundadoras, embora insuficiente para um panorama completo do respectivo programa, deverá mesmo assim permitir uma primeira percepção do esforço em curso para replicar com criaturas artificiais alguns dos processos básicos que conformam a vida das criaturas biológicas do nosso mundo, humanos incluídos. Apesar de estarmos, assumidamente, muito longe de um grau satisfatório de realismo biológico, a robótica tem oferecido possibilidades de experimentação que são valiosas quando se estudam fenómenos que não são directamente acessíveis, designadamente devido ao seu carácter histórico.

Não obstante, existe um obstáculo de monta: processos que, na história natural estão dinamicamente imbricados uns nos outros, nas suas réplicas artificiais encontram-se separados. Por exemplo, as experiências em robótica evolutiva e em robótica do desenvolvimento realizam-se em condições de quase completa separação experimental e, em larga medida, também de separação teórica. Quer dizer, um processo é estudado no pressuposto de que pode ser separado das influências mútuas com outros processos. Por um lado, essa separação teórica é legítima e até necessária para fazer avançar a investigação: a psicologia do desenvolvimento humano não tem que atender ao que poderia ter sido diferente se a evolução da espécie nos tivesse configurado morfológica e cognitivamente de outro modo. Por outro lado, um elevado grau de separação experimental resulta de verdadeiras dificuldades técnicas, que relevam, por exemplo, da necessidade de novos materiais que permitam replicar melhor as características dos tecidos dos corpos animais; ou da necessidade de soluções mais eficientes para processos computacionais muito exigentes. Por exemplo, muitos dos obstáculos a experiências mais realistas de evolução artificial de populações de robots estão relacionados com limitações impostas pelos materiais inorgânicos

${ }^{7}$ Uma visão abrangente das experiências de evolução da linguagem em robots encontra-se em Vogt (2006). 
disponíveis; e esses obstáculos tornam-se ainda mais gigantescos se pensarmos em cruzar processos evolutivos com processos de desenvolvimento pós-natal. Mesmo compreendidas as razões destas dificuldades, permanece a questão: na medida em que as ciências do artificial tentem compreender esses vários processos na sua forma geral, e não (apenas) na forma contingente como eles acabaram por acontecer neste mundo, terão de enfrentar a um nível fundamental o problema da conexão entre diferentes dimensões da história da vida que têm lugar em escalas temporais muito diferentes, como a evolução de uma espécie, o desenvolvimento dos espécimes dessa espécie, a história institucional de uma sociedade ou a aprendizagem dos indivíduos.

A ideia, tentadora, de podermos experimentar livremente com a dimensão temporal das experiências, por exemplo compactando o tempo por via computacional, provavelmente passando pela criação de mundos biológicos virtuais onde o decorrer do tempo virtual pudesse ser manipulado, enfrenta várias dificuldades.

Uma categoria de dificuldades tem a ver com a credibilidade da simulação, uma velha questão metodológica e epistemológica no seio das ciências do artificial. Algumas das experiências em que estamos envolvidos no ISR/IST com colectivos de robots (para a mais recente cf. Pereira et al., 2010), usando os pequenos robots e-puck (Mondada et al., 2009), recorrem a um processo de iteração entre fases experimentais com robots reais no mundo físico exterior aos computadores e fases experimentais em ambientes virtuais, com modelos pré-definidos do mundo físico e dos próprios robots. Necessitamos da simulação para poupar tempo na afinação e teste dos programas de controlo, para podermos cortar o tempo em fatias, para repetir a experiência no ambiente controlado do software: parar a experiência num dado ponto, repetir uma dada fase para observação pormenorizada e correcção pontual, repetição incessante da mesma experiência para comparação estatística. A simulação praticada (com o software Webots - http:// www.cyberbotics.com/) é considerada realista, num sentido muito preciso: o programa usado no controlo dos robots virtuais é exactamente o mesmo usado no controlo dos robots reais a operar no mundo físico. Mesmo assim, a quantidade de acontecimentos no mundo real que introduzem caminhos inesperados, face às experiências em simulação realista, torna pouco aconselhável epistemologicamente qualquer afastamento significativo do controlo das experiências pela sua execução no mundo real. Neste caso em que lidamos com robots bastante simples, o principal ponto de dificuldade 
está na modelação do mundo físico. É difícil antecipar as consequências de cada uma das inúmeras simplificações que esse exercício sempre envolve. Por exemplo, um pequeno acidente de relevo na arena experimental pode bloquear um robot, do mesmo modo que o peso de um robot numa superfície flexível pode libertar outro robot que tinha ficado preso. A acumulação de contingências tão simples como estas, que muitas vezes escapam aos modelos do mundo físico implementados computacionalmente, podem ditar resultados completamente diferentes para uma série de experiências. Houve um tempo em que havia na comunidade da investigação em Inteligência Artificial quem pensasse que a resolução desse problema seria relativamente acessível. Veja-se o projecto de formalização da física do senso comum (Hayes, 1979) e o diagnóstico do seu rotundo fracasso, que veio mesmo de entre os que partilharam essa ambição (McDermott, 1987). Esse optimismo está hoje quase extinto. Em abordagens ainda mais formalizadas, como é o caso da investigação em Vida Artificial, orientada pela ideia de que a vida é basicamente uma questão de forma, corremos o risco, mencionado por John Maynard Smith, de construirmos um tipo de ciência sem ligação a qualquer tipo de factualidade ${ }^{8}$. Se pretendermos saber como as coisas se passam neste nosso mundo, e não (apenas) como poderiam ter-se passado em algum mundo possível, temos de admitir que o recurso à simulação, apesar da sua utilidade heurística, é ainda difícil de dominar epistemologicamente quando nos afastamos do confronto mais ou menos sistemático do virtual com o real - e esse afastamento, em escalas temporais como a da evolução ou mesmo da história das instituições, é praticamente inevitável.

Parte das dificuldades do estatuto metodológico e epistemológico da simulação radicam num problema geral que impende sobre qualquer tentativa de modelização de processos históricos. Esse problema envolve a noção de "factos históricos inertes". Factos históricos inertes são factos que, no que toca às leis físicas, podiam ter sido de uma maneira ou de outra sem deixar qualquer efeito subsequente. Por exemplo, num computador digital, as diferenças de voltagem que não afectam a distribuição dos eventos elementares pelas categorias 0 e 1 nunca poderão, passado o momento da sua ocorrência, fazer qualquer diferença no futuro (Dennett, 2003). Do ponto de vista de um observador, são inertes, para um dado processo histórico,

${ }^{8}$ John Maynard Smith, segundo citação em Horgan, 1995, terá afirmado: “Artificial Life is basically a fact-free science". 
todos os factos que sejam desprezados pelos modelos que utilizamos. Ora, o problema está na quantidade massiva de contingência que assim é eliminada, comparativamente com processos reais no mundo natural. As experiências com hardware evolutivo mostram que mesmo dentro de um computador digital o controlo dos factos históricos inertes implica um enorme esforço conceptual e técnico (Tan et al., 2004; Gordon e Bentley, 2002).

A mesma questão pode ser posta para processos históricos ao nível institucional ou cultural em sociedades humanas. Neste domínio da realidade, qualquer sequência de eventos banais inclui inúmeros factos inertes, que não serão tidos em conta em simulação, porque terão de ficar de fora de qualquer algoritmo razoável para lidar com a situação (o qual, nomeadamente, terá de atender às limitações da capacidade de processamento dos agentes), mas que poderão condicionar o futuro da história contingente do processo. Uma parte relevante da noção de responsabilidade pelos nossos actos está ligada às consequências aparentemente inertes de decisões e acções cujos efeitos não são imediatamente compreensíveis: as consequências eventuais de actos que parecem morrer neste momento mas podem emergir num momento futuro. (Veja-se o caso, em termos jurídicos, dos precedentes invocados para interpretar uma regra com uma lacuna).

Stephen Jay Gould (1989) defendia que uma história evolutiva pode sempre tomar inúmeros rumos em inúmeras encruzilhadas, pelo que, mesmo que voltássemos a correr a história deste mundo desde as mesmas condições iniciais, não voltaríamos a obter a mesma instância em cujo resultado vivemos. Trata-se de reservar um papel de grande relevo para a contingência. Se Gould estava certo, a dificuldade de lidar com o problema dos factos históricos inertes - ou que são tratados como inertes pelos modelos com que temos de trabalhar - é um problema metodológico difícil para as ciências do artificial.

Neste texto não temos a pretensão de dar uma resposta a esta dificuldade. O que queremos, isso sim, é sugerir, eventualmente a benefício mútuo das ciências do artificial e do estudo da base biológica do comportamento das criaturas naturais, que pode ser encontrado aí um campo de cooperação frutuosa: explicitando, a partir da etologia, questões que possam ser exploradas experimentalmente com criaturas artificiais e com os métodos das ciências do artificial; usando resultados de experiências com criaturas artificiais para sugerir questões à etologia. Sugere-se que um ponto que poderia beneficiar dessa cooperação seria, precisamente, a questão das interacções dinâmicas 
entre fenómenos em diferentes escalas temporais. As ciências do artificial teriam a ganhar em dar mais atenção a essa interacção dinâmica, inspirandose na etologia para começar a tentar ultrapassar a infeliz situação de estarem a considerar separadamente o que só pode ser entendido conjuntamente. Talvez a etologia tivesse a ganhar em poder inspirar abordagens experimentais a algumas das divergências teóricas subsistentes no tocante a essa dinâmica complexa entre processos ocorrentes em diferentes escalas temporais.

Esta possibilidade pode tornar-se crescentemente interessante, pelo menos se estivermos realmente a entrar de forma acelerada na era do design total. Como escreve (Cruz, 2002): “A era do 'design total' será, pois, a era onde tudo ou quase tudo parecerá ser o resultado de uma quase história natural, sendo ao mesmo tempo, contudo, inteiramente intencionado, inteiramente concebido e inteiramente desenhado. Ou seja, a cultura, no seu estado de 'design total' é a cultura na era do apagamento da fronteira entre natural e artificial, o momento em que, aquilo que é inteiramente intencionado pelo homem, tenderá a apresentar-se como puramente natural." Se a tendência for realmente essa, o que é sugerido pela aceleração das possibilidades - e do desejo - de mudarmos cada vez mais os nossos corpos e as nossas mentes, precisa-se urgentemente de outro tipo de relação entre ciências do artificial e ciências do natural. E é por aqui que vai a sugestão contida neste texto.

\section{Referências bibliográficas}

Aldrich, H. E.; Hodgson, G. M.; Hull, D. L.; Knudsen, T.; Mokyr, J.; Vanberg, V. J. 2008. In defence of generalized Darwinism. Journal of Evolutionary Economics, 18: 577-596.

Belpaeme, T.; Steels, L.; van Looveren, J. 1998. The construction and acquisition of visual categories. In: Birk, A.; Demiris, J. (eds.) Learning Robots (Proceedings of the 6th European Workshop on Learning Robots). Berlim, Springer-Verlag: 1-12.

Brooks, R. 2000. From robot dreams to reality. Nature, 406: 945-947.

Callan, R. 1999. The essence of neural networks. Harlow, Prentice Hall.

Cruz, M.T. 2002. O Artificial ou A era do design total. Interact [Online], 7. [Consultado em 30-01-10]. Disponível em: http://www.interact.com.pt/interact7/ ensaio/ensaio4.html. 
Dennett, D. 2003. Freedom evolves [tradução portuguesa: A Liberdade evolui. Lisboa, Temas e Debates, 2005].

Eibl-Eibesfeldt, I. 1997. Human ethology. Origins and prospects of a new discipline. In: Schmitt, A.; Atzwanger, K.; Grammer, K.; Schäfer, K. (eds.) New Aspects of Human Ethology. New York, Plenum Press: 1-23.

Floreano, D.; Mondada, F. 1996. Evolution of homing navigation in a real mobile robot. IEEE Transactions on Systems, Man, and Cybernetics - Part B: Cybernetics, 26(3): 396-407.

Floreano, D.; Mondada, F. 1998. Evolutionary neurocontrollers for autonomous mobile robots. Neural Networks, 11(7-8): 1461-1478.

Floreano, D.; Nolfi, S. 1997. Adaptive behavior in competing co-evolving species. In: Husbands, P.; Harvey, I. (eds.) Fourth European Conference on Artificial Life. Cambridge (Massachusetts), The MIT Press: 378-387.

Floreano, D.; Nolfi, S.; Mondada, F. 1998. Competitive co-evolutionary robotics: from theory to practice. In: Pfeifer, R.; Blumberg, B.; Meyer, J-A; Wilson, S.W. (eds.) From Animals to Animats 5: Proceedings of the Fifth International Conference on Simulation of Adaptive Behavior (Complex Adaptive Systems). Cambridge (Massachusetts), The MIT Press: 515-524.

Gardner, H. 1985. The mind's new science. A history of the cognitive revolution. New York, Basic Books.

Gordon, T. G. W.; Bentley, P. J. 2002. On evolvable hardware. In: Ovaska, S.; Sztandera, L. (eds.) Soft computing in Industrial Electronics. Heidelberg, Physica-Verlag: 279-323.

Gould, S. J. 1989. Wonderful Life [tradução portuguesa: A Vida é Bela. Lisboa, Gradiva, 1995].

Hayes, P. J. 1979. The naïve physics manifesto. In: Michie, D. (ed.) Expert systems in the Micro-Electronic Age. Edinburgh, Edinburgh University Press: 242-270.

Hodgson, G.; Knudsen, T. 2006. Why we need a generalized Darwinism, and why a generalized Darwinism is not enough. Journal of Economic Behavior and Organization, 61(1): 1-19.

Holland, J. 1975. Adaptation in natural and artificial systems. Cambridge (Massachusetts), The MIT Press.

Horgan, J. 1995. From complexity to perplexity. Scientific American, 6: 74-79.

Lipson, H.; Pollack, J. B. 2000. Automatic design and manufacture of robotic lifeforms. Nature, 406: 974-978. 
Lipson, H.; Pollack, J. B. 2000. The Golem Project. [Online]. CS Department, Brandeis University [Consultado em: 29-12-2009]. Disponível em: http:// demo.cs.brandeis.edu/golem.

Lungarella, M.; Metta, G.; Pfeifer, R.; Sandini, G. 2003. Developmental robotics: a survey. Connection Science, 15(4): 151-190.

McDermott, D. 1987. A critique of pure reason. Computational Intelligence, 3: 151-160.

Mitchell, M. 1998. An introduction to genetic algorithms. Cambridge (Massachusetts), The MIT Press.

Mondada, F.; Bonani, M.; Raemy, X.; Pugh, J.; Cianci, C.; Klaptocz, A.; Magnenat, S.; Zufferey, J.-C.; Floreano, D.; Martinoli, A. 2009. The e-puck, a robot designed for education in engineering. In: Proceedings of the 9th Conference on Autonomous Robot Systems and Competitions, vol. 1(1). Castelo Branco, Instituto Politécnico de Castelo Branco: 59-65.

Nolfi, S.; Floreano, D. 1998. Coevolving predator and prey robots: do 'Arms Races' arise in Artificial Evolution? Artificial Life, 4(4): 311-335.

Nolfi, S.; Floreano, D. 2000. Evolutionary robotics - the biology, intelligence, and technology of self-organizing machines. Cambridge (Massachusetts), The MIT Press.

Pereira, J. N.; Christensen, A. L.; Silva, P.; Lima, P. U. 2010. Coordination through institutional roles in robot collectives. In: van der Hoek, W.; Kaminka, G.A.; Lespérance, Y.; Luck, M.; Sen, S. (eds.) Proceedings of 9th International Conference on Autonomous Agents and Multiagent Systems (AAMAS 2010), May, 10-14. Toronto, Canada: 1507-1508.

Sandini, G.; Metta, G.; Vernon, D. 2004. RobotCub: an open framework for research in embodied cognition. In: Proceedings of Humanoids 2004 (IEEE-RAS/RSJ International Conference on Humanoid Robots). Los Angeles, Novembro de 2004: 13-32.

Schopman, J. 1987. Frames of artificial intelligence. In: Bloomfield, B. P. (ed.) The Question of Artificial Intelligence - Philosophical and Sociological Perspectives. Londres, Croom Helm: 165-219.

Steels, L. 2001. Language games for autonomous robots. IEEE Intelligent systems, 16(5): 16-22.

Steels, L. 2003. Intelligence with representation. Philosophical Transactions of the Royal Society (Mathematical, Physical and Engineering Sciences), 361(1811): 2381-2395. 
Steels, L.; Vogt, P. 1997. Grounding adaptive language games in robotic agents. In: Husbands, P.; Harvey, I. (eds) Proceedings of the Fourth European Conference on Artificial Life, ECAL'97. Cambridge (Massachusetts), The MIT Press: 474-482.

Steels, L.; Kaplan, F.; McIntyre, A.; van Looveren, J. 2002. Crucial factors in the origins of word-meaning. In: Wray, A. (ed.) The Transition to Language. Oxford, Oxford University Press: 252-271.

Tan, K. C.; Wang, L. F.; Lee, T. H.; Vadakkepat, P. 2004. Evolvable hardware in evolutionary robotics. Autonomous Robots, 16: 5-21.

Teuscher, C.; Mange, D.; Stauffer, A.; Tempesti, G. 2003. Bio-inspired computing tissues: towards machines that evolve, grow, and learn. BioSystems, 68(2-3): 235-244.

Vogt, P. 2006. Language evolution and robotics: issues in symbol grounding and language acquisition. In: Loula, A.; Gudwin, R.; Queiroz, J. (eds.) Artificial Cognition Systems. Hershey, PA, Idea Group.

Zlatev, J.; Balkenius, C. 2001. Why 'Epigenetic Robotics'? In: Balkenius, C.; Zlatev, J.; Kozima, H.; Dautenhahn, K.; Breazeal, C. (eds.) Proceedings of the First International Workshop on Epigenetic Robotics: Modeling Cognitive Development in Robotic Systems. Lund, Lund University Cognitive Studies: 1-4.

Artigo recebido a 31 de Janeiro de 2010 e aceite a 28 de Abril de 2010. 